\title{
Leadership, corruption and the dignity of humans: Some reflections from the Nigerian context
}

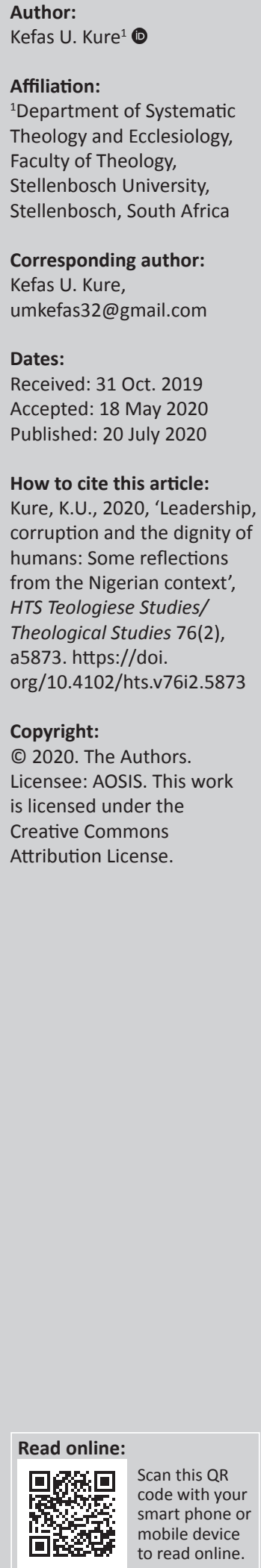

Leadership inadequacy in Nigeria has contributed to the rise in corruption, which has undermined human dignity through insufficient provision of basic human needs. This happens because the leadership venerates self-interest to such an extent that enhancing human wellbeing is not considered important. To save Nigerians from this dilemma, this article calls for a new leadership ethics called 'responsible leadership', whose precepts protect and enhance human dignity and enforce adherence to the rule of law to curb the spread of corruption. This was carried out by surveying the present system of governance with its failures and how it has contributed to human dignity violations. It was found that poor leadership was responsible for the continuous spread of corruption and exposure of human dignity to violations through porous and inadequate provisions of basic human needs. However, this study concluded that new leadership ethics, which are inclusive and integrative, would appreciate and recognise the intrinsic worth of every human being, take its people from their present position to where they should be, and would reduce violation of human dignity purported through corruption.

Contribution: The article argued for a new ethos of leadership that is responsible in nature, encompassing, and intentionally people-centred, which takes people from where they are to where they ought to be. It fits into the scope of the journal by way of inter-connecting different topics to produce a unifying idea.

Keywords: Corruption; Nigeria; Ethics of responsibility; Public theology; Human dignity; Leadership.

\section{Introduction}

The year 2019 marked two significant events in Nigerian history. The first being the 59th year of independence since it took over power from colonial masters, and the second being 20 years of stable democracy after several years of military leadership. Thus, it was a good time to remember and reflect on the developmental progress of the nation between 1960 and 2019. Interestingly, one of the central themes of the conference ${ }^{1}$ was 'Leadership'. It invited us to reflect upon what we see happening in our local contexts. For the author, the pertinent issue was the leadership of Nigerian state, particularly concerning humanity's wellbeing and nature. Being mindful of the theme of the conference, the title of this article was chosen to characterise how leadership, particularly in Nigeria, contributes to this conference's subtitle, 'The first shall be last and the last first'.

It is the American systematic theologian, Schweiker (2004), who, after a careful observation that every work in ethics provides some account of what is going on, describes the time we live in. He observes that all travails of the 20th century, including the horrors of mass deaths and the terrors of tyranny, are informed by a sense that we live amidst a global whirl and confusion in which meaning and orientation are difficult to attain. Many people feel their hopes and dreams fade away in the dusk of this age of uncertainty. With these events, he raises concerns on why people of our age must orient their existence by the commitment to respect and enhance the integrity of human life. Perhaps the worries of our time drive them to seek comfort in the past, thinking it was better than the present. To these, Schweiker (2004:xi) imagines the 'time of many worlds' as the best description of such a world.

Similarly, Hauerwas (1983) attests to such periods with great concern for humanity. According to him, we live in a morally bankrupt age where what was at some time in the past unthinkable has become the norm. Moreover, we experience our world as so chaotic that we now feel that the only

1.This article is based on the paper presented at the annual conference of the Theological Society of Southern Africa (TSSA), entitled The Last Shall Be First Theological and Ethical Reflection on (Christian) Leadership, held in Pretoria, South Africa, 21-23 June 2019. 
alternative is for each person to choose or create the standards by which they could live. It is the time where theories of rationality and relativity of absolutes have gained momentum. Such is the world that Hauerwas (1983:5) worries, as there is a 'hunger for absolutes'. This gives us a glimpse into the moral fibre of society where everyone defines moral maxims for themselves. To this Hauerwas (1983:6) adds that it is extremely hard to maintain our moral identity because we feel pulled into different directions by our various roles and convictions, unsure of any coherence to our lives, and so become divided selves and more easily tempted to violence. In a world with such complexity, maintaining and protecting human moral identity becomes difficult. Bedford-Strohm's (2010:211) uneasiness is that it is a time where people are no longer bothered by the nagging concern to maintain and uphold human dignity. Indeed, these events remind us that we live in a precarious situation (Hauerwas 1983:5). With these happenings, one is left wondering why things continue this way and wonder whether something has gone wrong with our moral judgement. Although some may argue that this is only a reflection of the American-European context. Do we, in the African continent, experience any effects of global dynamics threatening our sense of morality?

The African context has not been exempted from the advancement of global dynamics as our signposts abound, ranging from rape, terrorism, religious fundamentalism, discrimination, nepotism, racism, xenophobia, ethnophobia, kidnapping, regionalism and, of course, corruption (De Villiers 2012). Moreover, vulnerability to violence and crime, natural disasters and abusive cultural practices that perpetuate hopelessness define our continent (Koopman 2010). Our continent is plagued with these concerns that keep exposing human lives to formidable dangers whilst undermining their dignity at various levels. With these concerns in mind, although speaking from a different context, the author resonates with the above-mentioned views of both Schweiker (2004) and Hauerwas (1983) that we are indeed through the time of many worlds. These events continue to hamper our socio-economic and socio-political advancements, but the effects matter little to our democracies and leaders. Instead, our politicians, and perhaps our leaders, despite their professed solidarity with the poor, are more interested in enriching themselves once they are elected, by exploiting available public resources rather than improving the plight of the poor (De Villiers 2010). That puts the focus of most of our democracies on self-gratification, instead of the wellbeing of humanity and their societies. It is based on the abuse of power and opportunity rather than human and national interests. Sadly, an alarmingly high number of politicians and government officials become rich as soon as possible - willing to cross the line of immoral behaviour and become involved in corruption (De Villiers 2010). Also, some would dare to say that this is a continental problem that differs from one state to the other. So then, how could it be in Nigeria?

At a point in time, Nigeria was described as the giant of Africa. Its gigantic prowess was characterised in terms of capacity to give direction and serve as an example for other parts of the continent. By capacity, Nigeria was, and probably still is, the largest economy, with a strong military force that several wars within the African continent had got a boost from, until relative peace ensued (Ottuh 2015; Sodiq 2017). However, the trend has changed. The pendulum of clock has changed its direction. Perhaps we could argue that it is the fulfilment of scripture, 'The first shall be last and the last be first'. Once it was a country giving direction and support to other African nations, but now could barely help herself? Wars and their likes were not common in Nigeria as they have become now. The once cherished country has turned to an object of shame and ridicule within a span of a few decades. It is indeed true that the Nigerian nation has presently lost its sense of honour and respect that it once had. This is partly because of leadership failure both within and across the globe (Chayes 2015). Hence, the need to return to the height from which the nation has fallen and to question the reasons for the demise of its prestige. This would mean looking back retrospectively at how it was in the past and returning to how it should be whilst thinking of its future prosperity.

However, how do we move forward without remembering the past? What is it about the past that concerns the future realities that we need to know? Are there methods to adequately think about the past? In his writings, Nürnberger (1998) talks about gaining freedom for the future. To gain freedom for the future, he says, we must shake off the shackles of the past. To gain directions for the future we must understand how we got to where we are. We need to know what has worked and what has failed. We must decide what we want to achieve and what we want to avoid. Better still, we need to reflect on what humankind is supposed to strive for if true and full humanity is to be experienced. That suggests a form of leadership with a strong wheel to direct people from where they are to where they should be, which in this article is called 'responsible leadership'.

Based on Nürnberger's (1998) viewpoint mentioned above, we could agree that what is needed in the Nigerian leadership landscape is a responsible leadership model that is concerned with regaining and upholding its lost respect, protection of lives and property, and the promotion of human dignity. This kind of leadership moves beyond living and acting out principles - it authentically seeks the wellbeing of humanity. This sums up the main argument of this article. To this end, the sections below guide this exploration. In a nutshell, this article comprises three main parts: The first provides a brief overview of Nigerian governance. The second reflects on corruption and human dignity in Nigeria. The third argues for a new leadership ethics followed by a brief conclusion to wrap up the discussion.

\section{Nigeria and democracy}

One of the dramatic changes in the history of Nigeria in the 21st century has been the leadership swap from military leadership to a democratic system of governance, which Nigerians welcomed with a sigh of relief. This move brought 
freedom from the totalitarian and military dictatorship that ruled for decades (Asaju 2014; Ukase \& Audu 2015). It was probably a similar feeling that occurred at the end of apartheid in South Africa, the end of colonialism and the end of the cold war, which had anticipations as Mugambi (1995) has stated in his theology of reconstruction. In the case of Nigeria, introduction of democracy brought with it anticipation, hope for privileges and dreams for better living, including 'freedom, equality, mass participation, and choice' (Asaju 2014:3; Ukase \& Audu 2015). It also brought with it anticipation for peace, unity, progress and freedom from the militarisation of past dispensation. Others thought of a human-friendly system of governance that would be welcoming, integrative, receptive and open so that all may be heard and treated with dignity, equity and respect. A system that is liberating in nature by which humanity could be redeemed from both herself and the shackles of human cruelty. Unfortunately, these hopes have been dashed by the perils of the period we are living in. The author sometimes wonders whether democracy was the better option in the first place.

In the year 1999, after a long historical military dispensation, Nigeria returned to a democratic system of governance (Aleyomi 2013; Asaju 2014). This confirms a process of governance that allows a broad mass of people to choose their leaders and, in turn, guarantees them a wide range of civil rights and dividends as suggested by some of its features (Asaju 2014). Better still, democracy, having in its tenets 'the government of the people by the people and for the people', is enough to have raised high expectations at its emergence (Aleyomi 2013:9). However, these are true of an ideal democratic system which 'rests on good governance, and whose determinant and policies bring about growth, stability, and the wellbeing of the citizens' (Asaju 2014:4). This has not been true in Nigeria, with Nigerians passing the 20-year mark of democracy and still counting, they are left waiting in eager expectations.

The twist from the above has kept many Nigerians distant from actualising a Nigeria that our past heroes suffered, sacrificed, dreamt of, and strived for; the greatness that could attract global attention, and above all, ensure human flourishing. Those were perhaps the wishes of the heroes who fought for the Nigerian state from their colonial masters. These dreams are on the verge of being swept under the carpet of self-centredness, nepotism, religious fanatism, ethnophobia and uncontrollable militarisation of the innocent. This gives rise to questions such as, 'what has gone wrong with the leadership, particularly within the longest democratic era the country has experienced in curtailing these menaces?' Pervasive as these occurrences are becoming, it is difficult to maintain a good societal moral fibre because those at places of leadership 'have little sense of promoting good, as far as moral leadership is concerned' (Kretzschmar 2007:20). In part, they tend to make laws suitable to protect their interests and wants whilst thinking less of the effects on others. The result is evident in the increase of societal moral decay, which seems acceptable within a 'weak-willed leadership' ideology. Some of these include the inability to encourage others, lacking interest in inspiring others, hesitance to improve, poor or lack of vision, self-centredness and irregularities in their judgement. In summary, one could call such leaders immoral - as 'those who may lead others on a self-destructive path or a road that leads to misery' (Kretzschmar 2007:20). That said, the above indicates one of the features which is also the problem of leadership and how it has affected the Nigerian society.

Another feature of Nigerian democracy that has affected its growth is the problem of identity politics in praxis. For the sake of this article, 'identity politics' refers to a political approach and analysis that is based on people prioritising the concerns most relevant to their particular interest, including religion, race, ethnic, culture, amongst others, and forming exclusive political alliances with others within their group. Such a description of identity politics suggests that it has become a key concept explaining what is going on in the affairs of the world today. But this dilemma of identity politics could be explained using the concept of 'identity', which Fukuyama (2018) could help with. In his book, Fukuyama (2018) suggests that identity politics arises when there is a failure in a governing institution to fully solve the problem of people's inherent craving for the recognition of their selfhood. Rather, as Kumar (2018:250) observes, 'Many people are preoccupied with the attempt to fulfil their political aspirations by placing increasing emphasis on the particular group with which they are part'. That way of treating people has implications that are detrimental to human and societal wellbeing. This is affirmed by Kumar (2018), who insists that because of this type of treatment, citizens come to see themselves primarily as members of an exclusive group whose utmost concern is to enhance and enlarge their territories. This explains the present day politics of Nigeria, which, instead of regarding oneself as citizens of the nation, one's religious, tribal or political affiliation defines and determines what one can receive. Nigerian politics fuels such an ideology so much that those belonging to specific political parties, religions or ethnicities receive special treatment, whilst excluded are those with culturally diverse backgrounds and differing belief systems, ethics and affiliations. Borrowing from human dignity terms, one receives either honour, respect or welfare in proportion to their affiliation and not by their being human, and thus denying them their dignity.

Such an understanding of human dignity is merely obtainable through personal talents and achievements, which according to De Lange (2007:214) is determined by modern culture, making it far deeper rooted in personality than was the case in the aristocratic past. As human dignity is viewed as such by modern culture, it becomes easily quantifiable for personal contribution, rather than having dignity for simply being a human being. Hence, such perception makes the dignity of a human being susceptible to the consequences of societal vices such as corruption.

Following the above argument, inadequate leadership and identity politics were discussed as a microcosm showcasing 
the Nigerian democratic leadership. The two features have contributed to the promotion of self-interest, greed and ineffectiveness over national interests and protection of human wellbeing. This has immensely contributed to poor infrastructure that ensures a continuous undermining of human dignity.

\section{Corruption and human dignity in Nigeria}

Does it matter if dignity is mentioned amidst these circumstances in Nigeria? How does it affect Nigarians anyway? Corruption in Nigeria, as explained by Asaju (2014), Moyosore (2015) and Ogbonnaya (2018), has become an all-too-familiar term - a phenomenon that has reared its ugly head in just about every community and institution. Hence, it has received different interpretations such as being a bane characterising the Nigerian democratic state with detrimental effects on human dignity (Asaju 2014; Ogbonnaya 2018; Ukase \& Audu 2015). In addition to the abovementioned points, we could also mention that corruption has perverted justice in such a way that it has eradicated opportunities that would have otherwise enabled the flourishing of human lives and society. In this context, lack of provision of basic human needs resulting in the undermining of human dignity is so prevalent that human dignity has become, what Brand (1999) calls the 'fabulous ghost' in his reference to salvation in African context. But then, let us reflect on a trajectory between the perils of corruption and human dignity.

As humanity goes through various forms of violations, including the perils of corruption, there is a great tenacity in the quest for recognition and enhancement of its dignity. Such determination is fuelled by the human quest to live truthfully and with full dignity, which increases flourishing. As Volf (2015:ix) suggests, the following three phrases - 'the life as lived well', 'the life that goes well', and 'the life that feels good', refer to flourishing, and these three are intertwined inextricably. These phrases indicate the yearnings of humanity which relate to the call for their dignity. Everyone desires conditions of peace and prosperity where life is lived void of threats, which provides a sense of dignity. Not only is it the essence of being human in its wholeness but also human dignity speaks of inherent and intrinsic human worth which every human being has and has to be protected, respected and promoted. Hence, respecting humans as moral beings implies 'demand for the omission of certain acts that violate my humanity or that of every other' (Wolbert 2007:174). Put another way, it means to accept that being human suffices for having human dignity (De Lange 2007). It is an innate quality that befits every human being, a quality inseparable from its humanity belonging to its very essence, not acquired by special faculties or performance (Wolbert 2007). Hence, human dignity as such has no price, no equivalent and no quantitative dimension.

In his description of human dignity from an African context, Koopman (2010) emphasises the provision of basic human needs as a way to enhance human dignity. The provision of these needs, in his imagination, would ensure a more humane environment conducive and suitable for humanity to thrive. Some of these needs include health, security, shelter, food and education. The provision of these needs would become an indication of a realised society that upholds norms for the enhancement of 'integrity of human life before God' (Schweiker 1995:33).

The basic human needs that Koopman (2010) has referred to are helpful to consider the extent of corruption in Nigeria. Being a nation blessed with rich human and natural resources, Nigeria's poverty level has skyrocketed in recent times. This could be ascribed to the following reasons. Firstly, the rate at which poverty rises in a nation with abundant resources is caused by mismanagement and misappropriation (Jev 2014; Ogbonnaya 2018). Secondly, poor leadership has resulted in misappropriation by the incompetence of personnel, poor policies and poor implementation of the few surviving policies (Moyosore 2015; Ogbonnaya 2018). The two problems highlighted above - poor leadership and misappropriation could be regarded as key factors in the uncontrollable level of corruption in Nigeria and the subsequent undermining of human dignity through the lack of provision of basic needs. The provision of these basic needs has become something like a nightmare in Nigeria as hope dwindles daily with lack of remorse from policymakers who lack morals and honour. These conditions, as suggested by Aleyomi (2013), Asaju (2014), Moyosore (2015) and Ogbonnaya (2018), are propelled by failure of leadership. As leadership in Nigeria has directed itself towards the gratification of selfish ambitions with complete disregard for human and societal wellbeing, the populace is left starving in poverty and compelled to live in derelict conditions, although they are a part of a country blessed with abundant human and natural resource. What ensues, however, is the abuse of human dignity. Thus, one could ask where the conscience is of those who took an oath of office to safeguard the dignity of human lives and uphold the statutes of the constitution. The answer exists in our earlier assertion that Nigerian leaders have sunk into the abyss of moral degradation - there is a complete 'loss of morals, conscience, and honour' - that once they acquired leadership, the needs of Nigerians no longer matter to them. Another crucial basic human need is security. As a feature of any modern and responsible nation, the security of citizens' lives and their property is an undebatable parameter. This, too, has been a major concern in Nigeria in recent times. Formally, it had the insurgency of the deadly Islamic fundamentalist group, Boko Haram, perpetrators of peaceful coexistence. More recently, however, the security challenge has taken a different dimension with a new terrorist group, the Fulani Herdsmen/Jihadists operating through kidnappings, raping and killings. In part, these two groups share some common features, namely, the killing of innocents, raping of women, destruction of places of worship, schools and homes, and leaving scores people in a desperate and pitiable state. Those barbaric activities leave the victims with intense insecurity with violation of human dignity. 
Thus, corruption is considered to be a threat for human dignity (Umaru 2019). Considering the current status quo, questions arise whether life matters anymore, but without having appropriate answers. With strength of its military and other security agencies, one is left wondering why these terrorist groups continue to operate freely in Nigeria with countless innocent lives lost daily.

In order to highlight the porous nature of Nigerian security agencies and the continuous spread of insurgency, Bappah (2015) highlights some noteworthy points. Firstly, he points out the 'erosion of professionalism', which he sums up as the recruitment of armed personnel without adequate skills and training to combat insurgency. Secondly, the poor handling of war by the military against the Boko Haram insurgency. This point is further supported by Ademowo (2015). Thirdly, as identified by Bappah (2016), is the lack of decisive leadership. The last point encapsulates the previous two because leadership is responsible for tackling the first two problems. Do these actions leave one questioning the interests of the nation's leadership in curtailing these menaces? Quoting Bappah (2016) again, whilst the security agencies are complaining about inadequate weaponry, the leadership is boasting of increasing the security budget. Whilst there are complaints about poor ammunition for the military, the armed bandits are parading in military uniforms with top-class, high-quality weapons (Bappah 2016). These scenarios beg the following questions - who is issuing military uniforms to these bandits? From where have they obtained better weaponry than the nations' security personnel? There is no doubt that this is because of porosity of leadership, which has failed to take its 'fundamental responsibility for the protection of lives and properties and to ensure the wellbeing of the citizens' (Ademowo 2015:224). An attitude that thinks less of developing the flourishing future because there are no substantial plans for the present. Leaders are short-sighted to ascertain the potentials and the will to develop them. It is such a leadership that has turned a blind eye to the cries and afflictions of the poor. Ajie and Gbenga (2015) attest that this type of short-sighted and corrupt leadership has brought Nigeria to a crossroad where every sort of ridicule is meted from within and outside the country. To say the least, it is this kind of leadership that has failed to inculcate rudiments of a better life, even when it is within its discretion. This form of leadership is referred to as 'irresponsible' leadership which disregards the enhancement of human life. In the context of this research, such leadership should be replaced by a 'responsible' model - one that intends to lead, is attuned to moral values and seeks to promote the good of common Nigerian citizenry. With these goals in mind, we claim that unless the ethos of irresponsible leadership are changed and replaced with a more responsible one, the nation would remain as it is today. This is argued next.

\section{A different leadership ethics}

In the last part of this article, the present author argues for a new leadership ethics in Nigerian context. Sound and responsible leadership promotes proactivity and arouses interest in its people. Such a leadership involves the concept of responsibility concerning the enhancement of human dignity. Gleaning from the previous sections of this study, the author argues for different leadership ethics - one that seeks human wellbeing above all else - to oppose all forms of corruption demeaning the dignity of humans. At its best, such a leadership engages, influences, inspires and promotes accountability and encourages active participation.

Leadership is an adventure that attracts interest and involvement. It has been defined differently by various authors but almost always with similar goals. A few of these are reviewed next. Sharma and Jain (2013) define leadership as a process by which a person influences other people to accomplish an objective and directs the organisation in a way that makes it more cohesive and coherent. Winston and Patterson (2006), after surveying disparities from existing definitions, provide an integrative definition of leadership. They see a leader as the one who selects, equips, trains and influences followers who have diverse gifts, abilities and skills and focuses them on the organisation's mission and objectives, and thus enabling them to willingly and enthusiastically expend spiritual, emotional and physical energy in a concerted coordinated effort to achieve the organisational mission and objectives.

One central feature of the above definitions is that leadership involves influencing for maximum productivity. Leadership as such calls for skills, the will to act, not to coerce others but to pilot the mission and objectives of the entity. This type of leadership is only achieved by humbly conveying a prophetic vision of the future in clear terms that resonate with the followers' beliefs and values in such a way that they would understand and interpret the future into the present period's action steps (Winston \& Patterson 2006:7). At such a point, a leader has to be good not merely by accomplishments but by their ability to envision what best suits the wellbeing of the followers in applying their leadership knowledge and skills (Sharma \& Jain 2013:310). Such a leader has different leadership ethics compared to those with no interest in human wellbeing or the protection of human dignity as goals to be achieved. Furthermore, the above definitions provide clarification on the process of equipping, training, influencing and selection as the responsibility of a leader who seeks development whilst envisaging the flourishing of both present and future realities.

From here we proceed to describe where different leadership ethics that are responsible fit into the ongoing conversation. In doing so, we employ perspectives from the ethics of responsibility and moral leadership to serve as a roadmap. This leadership ethos, as presented here, comprises responsible living and responsible action, but it also has a moral perspective. To address the perils that have been highlighted, it is argued that the current leadership ethos in Nigeria, in nature and praxis, is deficient. Furthermore, a responsible leadership ethos is open to accepting blame for 
wrong doings and praise for correct actions. Responsible leadership is concerned with the accountability of one's actions or inactions, whilst moral leadership is 'specifically leadership attuned to a moral value that promotes good' (Kretzschmar 2007:20).

In his ethics of responsibility, Bonhoeffer (2005) highlights what may be termed as 'responsible action' by using the concept of freedom. It is the freedom to act without the support of people, conditions or principles but considering all existing circumstances related to people, general conditions or principles. Simply put, it is a freedom from dependency where one is free to act from self-evaluation on the relevancy of issues. Such freedom enables them to create good of themselves and critically address all the issues. Some of these issues involve rightful decisions, examination of motives and the prospects of their outcomes. In some cases, these outcomes result in praiseworthiness, for instance, when the actions or inactions are fitting, or blameworthiness when the result of the actions or inactions disregards human intentions and wellbeing. When we consider Kretzschmar's (2007) idea of moral leadership, such freedom enables us to promote good, not evil, uphold justice over injustice and celebrate integrity over corruption; it also promotes human wellbeing over its destruction because these could, in moral terms, be classified as good actions. These could be termed good intentions and actions that warrant the agent to live a good life, as their actions lead to the good of others. In the context of this study, responsible actions refer to when a leader acts, speaks and responds when needed, to avoid being described irresponsible when they fail to act, as described by Bonhoeffer (2005). However, leaders that fail to act when they needed should be called 'immoral' because they are capable of leading communities on a self-destructive path heading to misery (Kretzschmar 2007). The action of a responsible leadership from the Nigerian context would include appropriate placement of correct people at fitting places for better performance whilst ensuring that rule of law is strictly adhered to. It would involve a hunger for national interest above individual identities; routine check and implementation of human-friendly policies; and working towards fixing infrastructure that enhances the wellbeing of citizenry and adheres to fixing porous security challenges. Adhering to the above proposal would ignite sensitivity in leaders who previously regarded only few to be more human than others.

Next to responsible action is accountability as a prerequisite for a new leadership model. It would interest us to know that accountability holds a substantive degree of space in human interaction. It tells how one manages both human and material resources under their care. It is the responsibility of one's actions towards others to inform who is responsible for certain actions and who is accountable for the consequences of those actions. This is known as a 'responsible sense of living' in this study. It determines one's attitude and demonstrates what they do. As ethics of living is portrayed in this article, it paves the way for innovation and builds individual mechanisms to respond to moral decisions, particularly those involving corruption and protection of human dignity. This article further argues indecisiveness as a failure of leadership, which adversely affects the development of policies. But even when the policies are made and implemented, a call for intentional adherence is another issue to be considered, thus making possible for a responsible living. In this case, leaders first ought to become beacons of the policies they have developed through their actions, and only then they would have moral ground to ensure that others follow suit. In other words, it is a call for leaders to live what they say.

Some of these actions include working, providing, leading, directing, coordinating, struggling and suffering for those whom one is responsible for, and leading them to where they should be. Kretzschmar (2007:18) describes people with such attitudes as 'leaders that take individuals and communities where they need to go towards wholeness of life'. Any attempt to stand aloof of these responsibilities is a denial of the fact that one is responsible (Bonhoeffer 2005). Inability to put this together is 'the cost of moral leadership that only a few are willing to pay the price', but this what is required of leadership (Kretzschmar 2007:18). To say the least, what is seen lacking is responsible action (ability to take right decisions at appropriate time) and responsible living (ability to give account for one's actions or inactions, and to lead by example). These two put together leads to responsible leadership ethics, required most now, particularly in the Nigerian context.

\section{Conclusion}

This article proposes a twofold responsible leadership model, namely responsible action (ethics of doing) and responsible living (ethics of living) for the Nigerian context. This model of leadership prioritises interests of the nation with respect to the wellbeing of its citizens and the future through adequate planning for the continuous flourishing of Nigerian society. This is carried out by briefly reviewing Nigeria's past and comparing it with what is happening now in terms of corruption and the ensuing impact on the dignity of its citizens.

Central findings allude to certain attributes being responsible for what we experience today in Nigeria. Firstly, this study reveals that indecisiveness of leadership results in 'irresponsible action'. This is the inability to act, speak, direct and motivate others towards a more proactive and productive pathway. Secondly, 'irresponsible living' is the attitude of not living by example as portrayed by Nigerian leaders. Such an attitude makes it difficult to ensure that others behave appropriately. These two attitudes of leadership, amongst other things, have resulted in the perpetuation and spread of corruption in Nigeria. The detrimental effects of this could be seen in the lack of provision of basic human needs for its citizenry resulting in the continual undermining of human dignity through different spheres. Such a leadership has neither succeeded in helping the Nigerian citizenry nor 
brought them to the brim of democratic era they have clamoured for. Thus, a leadership which is inclusive, integrative, appreciates and recognises the intrinsic worth of every human being, takes people from where they are to where they should be, is imperative for Nigeria.

\section{Acknowledgements Competing interests}

The author declares that he has no financial or personal relationships that may have inappropriately influenced him in writing this article.

\section{Author's contributions}

K.U.K. is the sole author of this research article.

\section{Ethical considerations}

This article followed all ethical standards for a research without direct contact with human or animal subjects.

\section{Funding information}

The views and opinions expressed in this article are those of the author and do not necessarily reflect the official policy or position of any affiliated agency of the author.

\section{Data availability statement}

Data sharing is not applicable to this article as no new data were created or analysed in this study.

\section{Disclaimer}

The views and opinions expressed in this article are those of the author and do not necessarily reflect the official policy or position of any affiliated agency of the author.

\section{References}

Ademowo, A.J., 2015, 'Boko Haram insurgency and the imperative of promoting a culture of peace in Nigeria', The International Journal of Business \& Management $3(8), 224-229$.

Ajie, H.A. \& Gbenga, O., 2015, 'Corruption and economic growth in Nigeria: An empirical analysis', European Journal of Business and Management 7(5), 224-243.

Aleyomi, M.B., 2013, 'Corruption and democratization process in Nigeria's fourth republic', International Journal of Politics and Good Governance 4(4), 1-25.
Asaju, K., 2014, 'Sustaining democratic rule in Nigeria: The corruption tide', Advances in Social Sciences Research Journal 1(2), 1-12. https://doi.org/10.14738/assrj.12.51

Bappah, H.Y., 2016, 'Nigeria's military failure against the Boko Haram insurgency', African Security Review 25(2), 146-158. https://doi.org/10.1080/10246029.2016. 1151799

Bedford-Strohm, H., 2010, 'Human dignity: A global ethical perspective', Scriptura 104, 211-220.

Bonhoeffer, D., 2005, Ethics (Deitrich Bonhoeffer works), vol. 6, Fortress Press, Minneapolis, MN

Brand, G., 1999, 'Salvation in African Christian theology: A typology of existing approaches', Exchange 28(3), 193-223. https://doi.org/10.1163/157254399X00014

Chayes, S., 2015, Thieves of state: Why corruption threatens global security, W.W. Norton \& Company, New York, NY.

De Lange, F., 2007, “"Having faith in yourself": Self-respect and human dignity', Scriptura 95(1), 213-223.

De Villiers, E., 2010, 'Prophetic witness: An appropriate mode of public discourse in democratic South Africa?', Theological Studies 66(1), 1-8. https://doi.org/ 10.4102/hts.v66i1.797

Fukuyama, F., 2018, Identity: Contemporary identity politics and the struggle for recognition, Profile Books, London.

Hauerwas, S., 1983, The peaceable kingdom: A premier in Christian ethics, University of Notre Dame Press, Notre Dame, London.

Jev, A.A., 2014, 'Politics, conflict and Nigeria's unending crisis', Journal of Global Peace and Conflict 2(1), 147-158.

Koopman, N., 2010, 'Human dignity in Africa: A Christological approach', Scriptura 204, 240-249. https://doi.org/10.7833/104-0-184

Kretzschmar, L., 2007, 'The formation of moral leaders in South Africa: A Christianethical analysis of some essential elements', Journal of Theology for Southern Africa 128, 18-36.

Kumar, V., 2018, 'Citizenship, violence, and identity politics', Sociological International Journal 2(3), 245-255. https://doi.org/10.15406/sij.2018.02.00055

Moyosore, S.O., 2015, 'Corruption in Nigeria: Causes, effects, and probable solutions', Journal of Political Science and Leadership Research 1(8), 22-35.

Mugambi, J.N.K., 1995, From liberation to reconstruction: African Christian theology after the cold war, East African Educational Publishers, Nairobi.

Nürnberger, K., 1998, Beyond Marx and market: Outcomes of a century of economic experimentation, Cluster Publications, Pietermaritzburg.

Ogbonnaya, A.K., 2018, 'Effect of corruption in Nigeria economy: A critical view', International Journal of Academic Research in Business and Social Sciences 8(6), 130-128. https://doi.org/10.6007/IJARBSS/v8-i6/4191

Ottuh, J.A., 2015, 'A giant without gallantry: A rhetorical-biblical depiction of Nigeria as the giant of Africa', International Journal of African Society, Cultures, and Traditions 2(2), 41-55.

Schweiker, W., 1995, Responsibility and Christian ethics, University Press, Cambridge.

Schweiker, W., 2004, Theological ethics and global dynamics: In the time of many worlds, Blackwell, Hoboken, NJ.

Sharma, M.J. \& Jain, S., 2013, 'Leadership management: Principles, models, and theories', Global Journal of Management and Business Studies 3(3), 309-318.

Sodiq, Y., 2017, 'Nigeria, the giant of Africa', in Y. Sodiq (ed.), A history of the application of Islamic law in Nigeria, pp. 1-25, Palgrave Macmillan, Cham.

Ukase, P. \& Audu, B., 2015, 'The role of civil society in the fight against corruption Nigeria's fourth republic: Problems, prospects, and the way forward', European Scientific Journal 11(2), 171-195.

Umaru, K.K., 2019, 'Corruption as a threat to human dignity: Some reflections on the Nigerian situation', in S.B. Agang, P. Pillay \& C. Jones (eds.), A multidimensional perspective on corruption in Africa: Wealth, power, religion, and democracy, perspective on corruption in Africa: Wealth,
pp. 224-240, Cambridge Scholars, Newcastle.

Volf, M., 2015, Flourishing: Why we need religion in a globalized world, Yale University Press, New Haven, CT.

Winston, B. \& Patterson, K., 2006, 'An integrated definition of leadership', Journal of Leadership Studies 1(2), 6-66.

Wolbert, W., 2007, 'Human dignity, human rights, and torture', Scriptura 95, 166-176. 